\title{
Critical Thinking Dispositions and Learning Styles of Baccalaureate Nursing Students and its Relation to Their
}

\section{Achievement}

\author{
Hala Gabr Mahmoud \\ Assistant Professor, Nursing Administration Department, Faculty of Nursing, Mansoura \\ University, Egypt
}

Accepted: January 15, 2011 Published: February 13, 2012

Doi:10.5296/ijld.v2i1.1379 URL: http://dx.doi.org/10.5296/ijld.v2i1.1379

\begin{abstract}
Background: In a contemporary healthcare environment characterized by rapidly-changing developments and relentlessly-increasing knowledge, professional nurses need to develop critical thinking skills that will provide them with expertise in flexible, individualized, situation-specific problem solving. Therefore, nursing education strives to facilitate the development of students' critical thinking through the appropriate instructional approaches. Developing critical thinking and knowledge of different learning styles among the student population are important in designing curricula, and adopting teaching methods that to promote student learning is a crucial part of ensuring that students engage positively with content and develop the deep learning skills needed for lifelong learning. Assessment of LS and CTD should be given more attention by nurse educators because teaching students according to their learning ability will nurture their CTD, increase their ability to process information, and enhance academic performance. Aims: The present study aims to determine baccalaureate nursing students' critical thinking dispositions and learning styles and its relation to their achievement. Design: The study will use descriptive correctional study. Methods: The study was conducted at Faculty of Nursing at King Khalid University, Saudi Arabia. All nursing students, enrolled in the Faculty of Nursing from three levels of academic year, fourth, sixth, and eighth at the time of the study of the academic year 2010-2011 were included in the study $(n=208)$. Three tools were used for data collection namely; California Critical Thinking Disposition Inventory (CCTDI), Learning Style Questionnaire (LSQ), and Retrospective Audit. Results: Based on the study findings of this study, it could be found that there was no significant relationship between overall critical thinking dispositions and learning style with nursing students' achievement, while a significant relationship was proved between nursing student critical thinking disposition and nursing student active/reflective learning style. The majority of the undergraduate nursing students at Faculty of Nursing, King Khalid University
\end{abstract}


showed ambivalent disposition towards most of the dispositional characteristics and the overall CCTDI. Conclusions: It was concluded that critical thinking is enhanced when active learning approaches and most nursing students preferred active/reflective learning style. It is recommended to the developed further studies in other faculties of nursing in Saudi Arabia.

Key words: Nursing education program, critical thinking, critical thinking dispositions, learning styles, nursing students' achievement, nursing educators, Grade Point Average.

Abbreviations: CT critical thinking, CCTDI California Critical Thinking Disposition Inventory, LS learning style, GPA grade point average, SDL self-directed learning, SDLERS Students' Self-Directed Learner Readiness Scale.

\section{Introduction}

Over the past decade, nursing education is facing continuous challenges to prepare the kind of nurse who can accept the ambiguities of the modern health care world in which uncertainties necessitate frequent judgments with ethical and moral dilemmas. The nurse sought from nursing education is one who can act and reflect and who has the nature of compassionate scholar with an ever inquiring and expanding mind. A significant factor in the major changes in nursing education has been the notion of facilitating learning rather than the transmission of facts and of helping students to learn how to learn rather than encouraging rote teaching (Abu-Moghli et al., 2005).

Nursing is a profession where knowledge and practice do not remain static but are ever changing. It can be argued that nurse education should enable students to become effective lifelong learners equipped with the learning skills required for their profession. This can be achieved in different ways as by nurse educators knowing their students' learning style preferences and applying this knowledge in the selection and utilization of teaching, learning and assessment strategies to enable them to develop beyond their learning style comfort zone and become more flexible in their learning range (Fleming, 2010).

Developing critical thinking and knowledge of different learning styles among the student population are important in designing curricula, and adopting teaching methods that to promote student learning is a crucial part of ensuring that students engage positively with content and develop the deep learning skills needed for lifelong learning. Academics are challenged to ensure that teaching strategies reflect the diverse nature of the student population and prepare nursing students with the knowledge to be safe, competent, beginning practitioners who are work ready(Meehan-Andrews.2009).

In a contemporary healthcare environment characterized by rapidly-changing developments and relentlessly-increasing knowledge, professional nurses need to develop critical thinking skills that will provide them with expertise in flexible, individualized, situation-specific problem solving. Therefore, nursing education strives to facilitate the development of students' critical thinking through the appropriate instructional approaches (Yuan et al., 2008). The skill of critical thinking (CT) has become an increasingly prominent component of clinical nursing practice and nursing education. To meet the critical thinking criteria, faculties are continually challenged to develop and reflect on the effectiveness of teaching strategies that may enhance the development of critical thinking in students (Kawashima \& Petrini, 2004). 
Developing critical thinking skills in nursing is essential in establishing a scientific foundation for the profession, for creating a discipline in which truth is sought and implemented, and where use of theoretical perspectives are increasingly being tested and utilized. The power of critical thinking allows nurses to logically assess their own experiences and training and apply the results of this evaluation to patient care. The ability of nurses to cope with problems, their skills in determining patient needs and providing systematic care are all dependent upon their critical thinking skills (Kelly et al., 2010).

The conceptualization of critical thinking disposition was described in terms of seven traits namely; inquisitiveness, open mindedness, systematicity, analyticity, truth-seeking, critical thinking self-confidence, and maturity. These descriptions indicate that dispositional influences on thinking are multifaceted. In the first place, an interest in or enjoyment of thinking is a prerequisite for active engagement in thinking (inquisitiveness, need for cognition). Secondly, an open attitude underlies the willingness to consider different viewpoints and options before arriving at conclusions (open-mindedness, flexibility). Thirdly, a careful approach in thinking would certainly contribute to effective decision-making and problem-solving (conscientiousness, systematicity). Finally, values such as upholding fairness and truth fuel the striving for judgments that are sound and unbiased (truth-seeking, fair-mindedness). These four dimensions of thinking disposition emphasize different aspects of an individual's response to situations that call for thinking (Facione \& Facione,2001).

Competence in critical thinking is one of the expectations of nursing education. It is a part of professionalism and included within undergraduate nursing school curricula and is a part of the criteria for the accreditation and assessment of undergraduate and graduate nursing education programs. Determining the critical thinking levels of students in undergraduate nursing schools is important in terms of planning interventions in this area and establishing the methods of education that should be used (Ozturk et al., 2008). Soon after this, healthcare accreditation agencies around the world moved to include critical thinking as a requirement for nurses when making clinical judgments concerning care provision (Simpson \&Courtney,2008).

One of the objectives of nursing education is to produce nurses with the ability to think critically and thus be able to provide safe nursing care. Nurses today are expected to use critical thinking skills to make judgments about patient situations and act upon those judgments on a daily basis. Nurses must weight multiple pieces of evidence and make quick decisions. Critical thinking has long been considered an important part of nursing education (Profetto-McGrath, 2003). Nursing graduates must have critical thinking skills in addition to a basic knowledge of nursing and the sciences to make the necessary clinical judgments (Shirrell,2008). The development of these skills requires different teaching and learning strategies. Critical thinking dispositions (CTD) and learning styles (LS) of student nurses are of major concern to nurse educators because it affects the teaching methods used in their development (Yuh-Shiow et al.,2011).

Higher education has endorsed learner-centered approaches and emphasizes that learners should come to know their own learning styles. For learning tasks, an effective strategy is to guide and enable learners to be effective learners to understand their own learning styles and to manage their own learning. Learning styles can be described as the way students begin to 
concentrate on, process, internalize, and remember new and difficult academic information (Sweet,2009). Learning styles can also be defined as dominant/non dominant. Where the dominant learning style is defined as, a learning style score that falls into the strong or very strong category (Astin et al., 2006).

Students' learning styles are a major consideration in planning for effective and efficient learning. If more attention is paid to the individual's different learning styles, students will learn more effectively. Therefore, teacher should be aware of the students (Li et al., 2008). Indeed the ability to utilize several learning styles is advocated as it enables individuals to become effective, flexible, resourceful all round learners and professionals who can benefit from a wide range of learning opportunities utilizing whatever combination of learning styles the learning situation requires (Fleming,2010). It is generally acknowledged that learning styles indicate an individual's preferred way of learning or how the individual acquires information (Felder \& Brent, 2005).

Nurse educators and researchers are becoming more interested in understanding and integrating students' learning styles into nursing curricula to promote satisfying learning experiences resulting in the formulation of criteria for academic excellence. The variety and distribution of learning styles is wide among nursing students' population. It seems sensible for educators to consider learners' characteristics and to monitor ways in which students say they learn best and to listen to their preferences. When the institutional understanding the difference between nursing students' CTD and LS may assist in creating flexible instructional strategies that allow for multidisciplinary working(Suliman,2006).

Assessment of LS and of CTD should be given more attention by nurse educators because teaching students according to their learning ability will nurture their CTD, increase their ability to process information, and enhance academic performance. Knowledge about students' learning preferences has potential usefulness for teachers for adjusting their teaching styles to maximize learning achievement. Research in CT and LS in nursing in Saudi Arabia is still scarce (Suliman,2006). Therefore the present study may significant for educators, student nurses and academic institutions, because it provides a foundation for nurse educators in their understanding of the differences between CTD and LS of nursing students, and consequently setting strategies to enhance their CT abilities and LS. And nursing students will become aware of their CTD and LS, which may enhance their learning experiences. Hence, the present study aims to determine the relationship between baccalaureate nursing students' critical thinking dispositions and learning styles and its relation to their achievement.

\section{Significant of the Study}

Students differ dramatically in how quickly and easily they learn new material. One theory often promoted to improve learning efficiency is learning style, which posits that students learn best when their particular learning styles are matched to correspondingly suitable learning environments. By knowing the learning styles of the students and by creating learning environments matched to those learning styles, educators could enhance learning. Understanding the various styles of learning that are used by nursing students also is important so that educators are able to adapt their mode of teaching to meet the needs of the students. In addition to learning styles, it is important for educators to have an understanding of critical 
thinking dispositions as they are required for making judgments about patients' complex health problems. One favored approach for attaining higher performance levels advocates matching teaching methods to student's learning styles. However, exposing students to a range of learning style experiences enhances their learning and assists them in becoming effective learners who can adapt to their multifaceted working and learning.

\section{Research Questions}

The specific research questions are:

1. What are the critical thinking dispositions and learning styles of baccalaureate nursing students?

2. What is the relationship between the variables of critical thinking dispositions, learning styles and nursing students' achievement?

\section{Aim of the Study}

The aim of the study was to determine baccalaureate nursing students' critical thinking dispositions and learning styles and its relation to their achievement.

\section{Design}

Descriptive correctional study design

\section{Setting}

The study was conducted at Faculty of Nursing, King Khalid University, Saudi Arabia. The Faculty of Nursing was established in 2008, and developed as a traditional comprehensive governmental institution. It included the mentioned teaching nursing departments; Medical-surgical nursing, Pediatric nursing, Obstetrics nursing, Primary nursing, Psychiatric nursing, Community nursing, and Nursing administration. In the last few years, Faculty of Nursing- King Khalid University follow accredit hours policy.

\section{Sample}

All nursing students, enrolled in the Faculty of Nursing from three levels of academic year, fourth, sixth, and eighth at the time of the study of the academic year 2010-2011 were included in the study. In the present study excluded the first year because in this year of undergraduate program, the students are expected to study and get qualified in the same subjects. But in the second year, the students have different specified subjects according to represented disciplines (e.g. Nursing, Medicine, Pharmacology, etc.) It comprised of 102 nursing students from fourth level, 63 nursing students from level six and 43 nursing students from level eight.

\section{Tools of data collection}

Three tools were used for data collection, namely; California Critical Thinking Disposition Inventory (CCTDI), Learning Style Questionnaire (LSQ), and Retrospective Audit.

\section{California Critical Thinking Disposition Inventory ( CCTDI)}

It was developed by Facione \& Facione (2001) update. It was used to collect data concerning the disposition of the undergraduate nursing students towards critical thinking, at the Faculty of Nursing, at King Khalid University, Saudi Arabia. It consists of two parts: 
Part I: It includes the demographic data of the students as students' name, age, educational level and academic year.

Part II: It consists of 75 items grouped into seven dispositional characteristics sub-scale. The first dispositional sub-scale was truth seeking, that means targets the disposition of being eager to seek the truth and courageous about asking questions and it includes (12 items). The second dispositional sub-scale was open-mindedness that means being tolerant of divergent views with sensitivity to the possibility of one's own bias and it includes (12 items). The third dispositional sub-scale is analyticity that means valuing the application of reason and use of evidence to resolve the problem even if the problem at hand turns out to be challenging or difficult and it includes (11 items). The fourth dispositional sub-scale was systematicity, that means targets the disposition towards organized, orderly, focused and diligent process in the inquiry stage and it includes (11 items). The fifth dispositional sub-scale was self-confidence that means trust one place in one's own reasoning processes and it includes ( 9 items). The sixth dispositional sub-scale was critical thinking inquisitiveness that measures one's intellectual curiosity and one's desire for learning and it includes (10 items). And finally dispositional sub-scale was maturity that means targets the disposition to make reflective judgment based on standards and context and evidences and it includes (10 items).

All items of the seven dispositional characteristics were scrambled. Students responded using a 6-point Likert scale ranging from "strongly agree" to" strongly disagree".

\section{Index learning style questionnaire (ILSQ)}

Learning style questionnaire was developed by Felder \& Soloman (2004). This questionnaire consists of 44 questions with forced-choice items with two options a and $b$. This questionnaire has four scales and focused to assess the learner's learning styles preferences, each with 11 items. The first scale was sensing (concrete, practical, oriented toward facts and procedures), or Intuitive (conceptual, innovative, oriented toward theories and underlying meanings). Second was visual (prefer visual representations of presented material, such as pictures, diagrams, and flow charts) or Verbal (prefer written and spoken explanations). Third was active (learn by trying things out, enjoy working in groups) or Reflective (learn by thinking things through, prefer working alone or with one or two familiar partners); and finally was sequential (linear thinking process, learn in incremental steps) or global (holistic thinking process, learn in large leaps).

\section{Scoring system}

The scoring of the full CCTDI scale of covers a range from70 up to 420 . Scores above 280 indicate a positive overall disposition towards CT. The total score between 210 and 280 indicates ambivalence towards CT and below210 indicates opposition towards CT. Sub-scale scores ranging from 30 down to 10 indicates a negative disposition. Scores between 40 and 30 indicate an ambivalent disposition towards CT. Scores on the sub-scales that are at 40 or above are considered as a positive disposition, with marks raging from 50 to 60 indicating strong positive disposition towards CT (Facione et al., 2001).

\section{III- Retrospective audit}

It was for identifying students' achievement for academic year 2010/2011. The student achievement is identified by using average grade point scale that is designed as accumulated form for assessing students' progress grades in the current years. 


\section{Methods}

- An official agreement was obtained from the Dean of the Faculty of Nursing, at King Khalid University, Saudi Arabia to collect the necessary data.

- The questionnaire was translated into Arabic and English questionnaires were submitted to three experts from English section, at King Khalid University, Saudi Arabia.

- Internal consistency reliability of the critical thinking dispositions sub-scales was assessed using coefficient alpha. It was 0.87 .

- Pilot study was carried out on 10 students selected randomly from the different academic levels to check and ensure the clarity of the Arabic questionnaire, identify obstacles and problems that may be encountered during data collection and to estimate the time needed to complete the questionnaire items.

- Data were collected from all undergraduate nursing students enrolled in level four, six, and eight at the Faculty of Nursing, King Khalid University to determine critical thinking dispositions and learning style. Needed instructions were given before the distribution of the questionnaire. The data collection took a period of three months, starts April 2011.

- Review the accumulative score of the studied sample from the pass sheet used by Faculty of Nursing, at King Khalid University, start from first academic year (2010/2011) to the current academic year of data collection.

\section{Statistical analysis}

Data was organized, computerized, tabulated, and analyzed using quantitative and qualitative analysis. The mean score and standard deviation for each seven characteristics and learning style dimension were measured. The ANOVA ( $F$ test) was used to compare the significant difference of the means for the characteristics. The overall CCTDI and learning style score, with level of significance $\mathrm{p} \leq 0.05$. The $\mathrm{t}$-test was used to compare the sample means to judge whether an observed difference is as a result of chance or as a result of significant difference.

\section{Results}

Table (1) shows mean and standard deviation of critical thinking disposition of nursing students in different academic levels. This table showed that there is a statistically significant difference regard total critical thinking disposition among nursing student in different levels $\mathrm{p}<0.05$. This table also shows there was no significant difference between studied nursing student regarding components of critical thinking disposition except truth seeking, systematicity, self-confidence and critical thinking inquisitiveness were significantly difference. As well as the highest mean score of the overall critical thinking disposition was 270.34 reported for nursing student in level eight and followed by nursing student in level four and six 268.79 and 260.38 respectively.

Table (2) shows mean and standard deviation of learning style of nursing students in different academic levels. This table showed that there is no statistically significant difference regard all style of learning among nursing student levels except active/reflective learning style was 
significantly difference $\mathrm{p}<0.05$. This table revealed that the highest mean score was 5.12 reported for visual/verbal learning style for nursing student enrolled in level six and followed by nursing student enrolled in level four 4.78 score. While the lowest mean score was .162 for sequential/global learning style for nursing student enrolled in level eight and followed by nursing student in level six and four .365 and .470 score respectively.

Table (3) depicts relationship between critical thinking dispositions and learning styles with nursing students' achievement. This table revealed there was not significantly relationship between overall critical thinking dispositions and nursing students' achievement. As well as most of the critical thinking dispositions components were significantly correlated with active/reflective learning style except systematicity, self-confidence, and critical thinking inquisitiveness disposition that were not significantly correlated. This table also showed critical thinking inquisitiveness was significantly correlated with sensitive/intuitive learning style.

Table (4) shows relationship between learning styles with overall critical thinking dispositions and nursing students' achievement. This table revealed that overall critical thinking disposition was not significantly correlated statistically with all learning style except active/reflects learning style that was significantly correlated. This table also showed nursing students' achievement not significantly correlated statistically with all learning style ( $p<0.05$ level).

Table (1) Mean and standard deviation of critical thinking disposition of nursing students in different academic levels $(n=208)$

\begin{tabular}{|c|c|c|c|c|}
\hline \multirow[t]{2}{*}{ Component } & \multicolumn{4}{|c|}{ Level } \\
\hline & $\begin{array}{l}\text { Fourth level } \\
\text { Mean } \pm \text { Sd }\end{array}$ & $\begin{array}{l}\text { Six level } \\
\text { Mean } \pm \text { Sd }\end{array}$ & $\begin{array}{l}\text { Eight level } \\
\text { Mean } \pm \text { Sd }\end{array}$ & $\begin{array}{l}\text { F } \\
\text { p value }\end{array}$ \\
\hline Truth-seeking & $43.519 \pm 4.480$ & $42.809 \pm 3.550$ & $45.604 \pm 4.488$ & $\begin{array}{l}5.860 * \\
0.003\end{array}$ \\
\hline Open-mindedness & $43.264 \pm 4.759$ & $43.555 \pm 4.655$ & $44.139 \pm 4.512$ & $\begin{array}{l}.530 \\
.589\end{array}$ \\
\hline Analyticity & $38.617 \pm 5.980$ & $36.873 \pm 3.598$ & $38.604 \pm 5.555$ & $\begin{array}{l}2.389 \\
.094 \\
\end{array}$ \\
\hline Systematicity & $40.862 \pm 4.923$ & $37.571 \pm 5.207$ & $37.767 \pm 5.380$ & $\begin{array}{l}10.301 * \\
.000\end{array}$ \\
\hline self-confidence & $29.784 \pm 4.055$ & $29.158 \pm 2.913$ & $31.116 \pm 3.080$ & $\begin{array}{l}3.940 * \\
.021\end{array}$ \\
\hline CT Inquisitiveness & $37.931 \pm 4.264$ & $36.492 \pm 2.850$ & $37.907 \pm 3.714$ & $\begin{array}{l}3.162 * \\
.044\end{array}$ \\
\hline Maturity & $34.813 \pm 4.843$ & $33.920 \pm 3.543$ & $35.209 \pm 5.383$ & $\begin{array}{l}1.164 \\
.314 \\
\end{array}$ \\
\hline Total & $268.7941 \pm 23.753$ & $260.381 \pm 17.342$ & $270.348 \pm 25.942$ & $\begin{array}{l}3.484 * \\
.033\end{array}$ \\
\hline
\end{tabular}

*Significant at $p<0.05$ level. 


\section{Macrothink $\Delta$ Institute ${ }^{\text {tm }}$}

Table (2) Mean and standard deviation of learning style of nursing students in different academic levels $(n=208)$

\begin{tabular}{|l|l|l|l|l|}
\hline \multirow{2}{*}{ Learning style } & \multicolumn{4}{|c|}{ Level } \\
\cline { 2 - 5 } & $\begin{array}{l}\text { Fourth level } \\
\text { Mean } \pm \text { Sd }\end{array}$ & $\begin{array}{l}\text { Six level } \\
\text { Mean } \pm \text { Sd }\end{array}$ & $\begin{array}{l}\text { Eight level } \\
\text { Mean } \pm \text { Sd }\end{array}$ & $\begin{array}{l}\text { F } \\
\text { p value }\end{array}$ \\
\hline Active/Reflective & $2.843 \pm 3.534$ & $1.222 \pm 4.206$ & $2.255 \pm 4.429$ & $\begin{array}{l}3.297 * \\
.039\end{array}$ \\
\hline Visual/Verbal & $4.784 \pm 3.732$ & $5.127 \pm 3.643$ & $3.837 \pm 4.412$ & $\begin{array}{l}1.487 \\
.229\end{array}$ \\
\hline Sensitive/Intuitive & $4.544 \pm 4.097$ & $4.015 \pm 4.014$ & $4.627 \pm 4.391$ & .405 \\
& & & & .667 \\
\hline Sequential/Global & $.470 \pm 3.503$ & $.365 \pm 4.843$ & $.162 \pm 3.031$ & .096 \\
& & & & .909 \\
\hline $\begin{array}{l}\text { Total learning } \\
\text { style scores }\end{array}$ & $12.656 \pm 10.053$ & $10.730 \pm 12.156$ & $10.883 \pm 12.553$ & .726 \\
.485
\end{tabular}

*Significant at $p<0.05$ level.

Table (3): Relationship between critical thinking dispositions and learning styles with nursing students' achievement $(\mathbf{n}=\mathbf{2 0 8})$

\begin{tabular}{|l|l|l|l|l|l|}
\hline \multirow{2}{*}{ Variable } & \multicolumn{5}{|c|}{ Learning Styles } \\
\cline { 2 - 6 } & $\begin{array}{l}\text { Active/ } \\
\text { Reflective }\end{array}$ & $\begin{array}{l}\text { Visual/ } \\
\text { Verbal }\end{array}$ & $\begin{array}{l}\text { Sensitive/ } \\
\text { Intuitive }\end{array}$ & $\begin{array}{l}\text { Sequential/ } \\
\text { Global }\end{array}$ & $\begin{array}{l}\text { Students' } \\
\text { achievement }\end{array}$ \\
\hline Truth-seeking & $-.121^{*}$ & -.027 & -.019 & -.057 & .017 \\
\hline Open-mindedness & $-.140^{*}$ & -.075 & -.043 & -.086 & .054 \\
\hline Analyticity & $-.118^{*}$ & -.042 & -.014 & -.023 & -.071 \\
\hline Systematicity & -.087 & -.079 & -.104 & -.020 & .101 \\
\hline self-confidence & -.105 & -.058 & -.063 & -.078 & .002 \\
\hline CT Inquisitiveness & -.035 & .002 & $.138 *$ & -.024 & .098 \\
\hline Maturity & $-.182^{* *}$ & -.020 & .010 & .008 & .009 \\
\hline
\end{tabular}

*Correlation is significant at the 0.05 level (2-tailed).

**Correlation is significant at the 0.01 level (2-tailed). 
Table (4): Relationship between learning styles and overall critical thinking dispositions with nursing students' achievement $(n=208)$

\begin{tabular}{|l|l|l|}
\hline & Critical thinking disposition & Students' achievement \\
\cline { 2 - 3 } & $\mathrm{r}$ & $\mathrm{r}$ \\
& $\mathrm{p}$ & $\mathrm{p}$ \\
\hline Active/ Reflective & $-.159 *$ & -.011 \\
& .020 & .878 \\
\hline Visual/Verbal & -.062 & .065 \\
& .376 & .352 \\
\hline Sensitive/Intuitive & -.019 & -.062 \\
& .789 & .376 \\
\hline Sequential/Global & -.053 & .055 \\
& .444 & .427 \\
\hline Total & -.104 & .040 \\
& .135 & .568 \\
\hline
\end{tabular}

*Correlation is significant at the 0.05 level (2-tailed).

\section{Discussion}

In nursing, the rapidly changing health care delivery and practices require sound critical thinking and decision making skills. It is necessary to provide students with the skills to seek, analyze and utilize information effectively. Students' learning styles are a major consideration in planning for effective and efficient learning (Yuh-Shiow Li et al., 2011). One of the objectives of nursing education is to produce nurses with the ability to think critically and thus be able to provide safe nursing care. Therefore, the critical thinking dispositions (CTDs) and learning styles (LS) of student nurses are of major concern to nurse educators because it affects the teaching methods used in their development(Suliman,2006).

Overall of the present study revealed that there was no significant relationship between overall critical thinking dispositions and learning styles with nursing students' achievement. While a significant relationship was proved between nursing student critical thinking disposition and nursing student active/reflective learning style and the majority of the undergraduate nursing students at Faculty of Nursing, King Khalid University regards of their academic year showed ambivalent disposition towards most of the dispositional characteristics. This mean that critical thinking dispositions not improved as the academic years progressed. This is agreed with Taha (2003) who found the majority of undergraduate nursing students' ambivalent disposition toward overall CCTDI. This is contrasted with Shin et al., (2006) findings who concluded that the critical thinking dispositions improved as the academic years progressed.

Critical thinking is thought to be a key component of nursing practice, education and knowledge (Ferol et al., 2010). Findings of the present study revealed that there was significant difference among nursing students for overall mean score of critical thinking dispositions as a result of a statistically significantly difference of the truth seeking, systematicity, self-confidence and critical thinking inquisitiveness. This is agreed with Taha (2003) who 
found a significant difference in relation to their mean score for all dispositional characteristics except self-confidence. As well as Profetto-McGrath (2003) who found that differed significantly on the truth seeking, confidence, analyticity, and inquisitiveness subscales. While Stewart \& Dempsey,(2005) found no significant differences in CCTDI scores from sophomore to senior years in a small study of baccalaureate nursing students. Therefore, Allen et al.,(2004) recommended nursing educators must be teaching students how to think critically in nursing. And Walsh \& Seldomridge,(2006) urged faculties to debate how content could be taught to foster the development of CT rather than what should be taught.

Again, findings of the present study revealed that no relation between critical thinking dispositions and nursing student achievement. Relying on this result, academic achievement can be considered to have no impact on critical thinking disposition. This is agreed with Emir (2009) who observed that the critical thinking disposition of the students does not show difference according to academic achievement. While Jackie et al., 2007) suggested that students with higher critical thinking skills will demonstrate greater academic success as demonstrated by greater persistence and higher nursing course Grade Point Average (GPA) than those students with lower scores. And Ferol et al., 2010 suggested that students with a strong overall critical thinking disposition and a greater ability to analyze a situation systematically perform better when faced with a clinical scenario that more closely mimics reality.

Determining the critical thinking levels of students in undergraduate nursing schools is important in terms of planning interventions in this area and establishing the methods of education that should be used (Ozturk et al., 2008). Several barriers to teaching for CT were found in baccalaureate programs including student resistance to active learning, inadequate class time, insufficient time to prepare CT activities, and need to cover content. Therefore, when evaluating curriculum in terms of its structure, emphasis needs to be placed on the quality of the content and how students are able to process and evaluate the information (Walsh \& Seldomridge,2006). This is the same view of Simpson \&Courtney, (2008) who advocated instructional strategies to foster critical thinking must be integrated into all levels of nursing curriculum such as concept maps, case studies, role-playing, and computer assisted instruction.

Qualified education should show the way to students about what and how to learn. While students evaluate what they learned and their learning methods, they manifest their critical thinking abilities. According to Walsh \& Seldomridge,(2006)mentioned that students are not passive but active while they are realizing critical thinking. If students use critical thinking skills, they gain clear and bright views in depth, they are more interested in events, they approach in a more reasonable manner and they become fairer.

Findings of the present study revealed that the highest score achieved by students was on the subscale of truth-seeking and open-mindedness. This may be contributed to student has a greater tendency to seek the truth, to question, to be objective even in the face of information that is contrary to his/her own thoughts. And open-mindedness given that the students are encouraged to question the teacher or each other and to maintain harmony in the classroom at all times. The students have more, if any, opportunity to engage in debate about divergent views. This is consistent with Cook (2005), Felder \& Spurlin, (2005) findings, which has reported that global learners who use non linear and holistic thinking are more likely to be 
intuitive learners. This result supported by Ozturk et al.,(2008) who found a high score of truth-seeking sub-scale and there was a significant difference between critical thinking disposition scores in the "open-mindedness" and "truth-seeking" subscales for nursing students in the two nursing schools where different educational models were being implemented.

Again findings of the present study revealed that analyticity and systematicity were found to score below the cut-off point of 40 . This may be contributed to educational system tended not to encourage independent inquiry, but rather compliance to the authority of the teacher, could have had an influence on the students' truth-seeking behavior. This is contrasted with Profetto-McGrath (2003) who reported the lowest scores achieved by students, was on the subscale of truth-seeking, while the highest were on inquisitiveness. While Shin et al., (2006) reported that Korean students tended to score high in inquisitiveness, self-confidence, and analyticity, but demonstrated poor ability in truth-seeking. And Suliman \& Halabi, (2006) reported analyticity, open-mindedness, systematicity, and inquisitiveness, were predominant critical thinking dispositions. Similar results have been found by Li et al., (2008) in Hong Kong and on mainland China.

Baccalaureate nursing students have been found to be "independent learners" or ones who desire to learn new things and are independent in identifying personal goals. The learning style might be influenced by the culture because of different socialization experiences (Abu-Moghli et al., 2005). This result supported by Li et al., (2008) who found the preferred styles of Taiwanese nursing students to be "sensing learners" and "judgment learners". Sensing learners tend to be interested in direct or objective perceptions made through the physical senses, while judging learners prefer a planning and organizing approach to solve problems.

Findings of the present study revealed self-confidence, critical thinking inquisitiveness, and maturity subscales were achieved by students with lowest score. It indicated that the students were weak in using an organized and focused manner of reasoning when problem-solving. Therefore findings of the present study may serve as an impetus to faculty members for the development of teaching/learning strategies that foster inquisitiveness instead of the passive teaching/ learning that takes place in a classroom and relies solely on lectures. The fact that the nursing educational system has tended to rely heavily on memorization, rather than analytical and systematic approaches to problem solving, most likely has contributed to these findings. Such findings suggest the need for the implementation of teaching/ learning strategies, such as problem-based learning, that could foster problem-solving abilities.

The variety and distribution of learning styles is wide among nursing students' population. It seems sensible for educators to consider learners' characteristics and to monitor ways in which students say they learn best and to listen to their preferences. A recognition of the strengths and weaknesses of individuals' learning styles by the individual concerned and the educator is the key to providing the appropriate learning experiences to develop those individuals. Knowledge about students' learning preferences has potential usefulness for teachers for adjusting their teaching styles to maximize learning achievement (Abu-Moghli et al.,2005).

The understanding of students' learning styles preferences would enable if possible a match to be made between their learning styles and the teaching styles of teachers. This means that 
understanding the various styles of learning that are used by nursing students is important so that educators are able to adapt their mode of teaching to meet the needs of the students. It is necessary for both the student and educational institutions to understand learning styles (Koch et al., 2011). Learning styles also influence the way in which learners master the goals and objectives of an educational programme (However, no one style is considered better than another (Rassool \& Rawaf, 2007).

Findings of the present study revealed that there was no significant difference among nursing students for learning styles. The majority of nursing students preferred visual/verbal learning style, while the minority preferred for sequential/global learning style. This may be due to the nursing students tending to look at PowerPoint presentations and textbook readings during classroom sessions. Perhaps the most important challenge for nurse education is to identify how we can enable students to use learning styles to their full effect and to create a balanced teaching approach that caters for the learning styles of all students but also seeks to stretch students beyond their learning style comfort zones in order to help them to maximize their learning potential during their undergraduate education and in their continuing professional development.

On the other hand Fleming et al.,(2010) found the preferred learning style of nursing students in their study both in their first and final year was reflector. Another study done by Zhang \& Lambert,(2008) found the most common dimensions of the four learning styles were found to be reflective, sensing, visual, and global. This implies that the students were likely to learn by thinking things through and working alone, use a concrete and practical orientation toward facts and procedures, prefer visual representations of presented materials, and use holistic thinking and learn in large leaps. This finding was somewhat similar to the study conducted by Tao \& Cui, (2007) who suggested that Chinese baccalaureate nursing students preferred to learn by reflective observation. However, Astin et al., (2006) found the most favored dominant learning style was activist.

Finding of the present study revealed that active/reflective was negatively correlated with truth seeking, open-mindedness, and analyticity, especially maturity was highly significantly correlated. While critical thinking inquisitiveness was positively correlated with sensitive/intuitive. This is contrasted with Zhang \& Lambert,(2008) who found self-confidence was positively correlated with visual learning and negatively correlated with verbal learning. This suggests that those who prefer visual presentations are inclined to trust their own reasoning process more than those who prefer verbal learning. Similar findings were found by Suliman \& Halabi, (2006) who suggested that self-confidence was positively correlated with abstract conceptualization. Conversely, intuitive learning was found to be negatively correlated with sequential learning and positively correlated with global learning. This has been a consistent finding of Cook (2005), Felder \& Spurlin, (2005), which has reported that global learners who use non-linear and holistic thinking are more likely to be intuitive learners.

In addition to Zhang \& Lambert,(2008) recommended that it is imperative for nurse educators to develop a curriculum that enhances students' ability to think critically throughout the nursing program. As students have various types of learning styles, it would be important to consider implementing a variety of teaching/learning strategies (case studies, clinical practice integrating with classroom experiences, role-playing, games, simulations, and problem-based 
learning), rather than relying on lectures. This could help meet the learning needs of a wider range of students and, in turn, hopefully enhance students' critical thinking abilities.

Assessing LS will identify how learners perceive, interact with and respond to the learning environment. Teaching students according to their learning ability will nurture their CTD, increase their ability to process information, and enhance academic performance (Suliman,2006). The results of the present study revealed that no significant correlation between learning styles and nursing students achievement. This is supported by Rassool \& Rawaf, (2008) who asserted that learning style is a weak predictor of academic performance. And they suggested many possible contributing factors to changes in learning style scores and development as the use of a variety of learning styles according to the subject being studied, the course design, the assessment strategy utilized and the influences of socialization and education during one's nursing career and a possibly the developmental growth process. Therefore Fleming et al., (2010) pointed to further research is required to determine the influence of these factors and also how reflective our findings are of the learning experiences of students prior to entry to the programme.

There are many nurse educators who have limited knowledge of teaching strategies that address the learning styles of students. This can lead to student and instructor frustration, poor academic performance, and high attrition rates among nursing students (Arthurs, 2007). Therefore Huxham (2005) emphasized on attention should be focused on limiting time spent lecturing to students and encouraging thinking through interactive and reflective exercises. Recognizing that students have different learning styles, and understanding the different styles, encourages lecturers to reflect on the effectiveness of lecture methods and prompts academics to consider adopting different teaching approaches to accommodate differing learning preferences as a means of enhancing student learning (Koch et al.,2011). And D'Amore et al., 2011 findings indicate the need for educators and students to be made aware of existing student learning styles, to encourage the development of a balanced learning style.

Adult students learn best and retain information when taught using a variety of instructional methods. Therefore Sweet (2009) recommended that finding the time to design lesson plans that accommodate the diversity of learning styles can be time intensive for educators. Moreover, educators can found that using a learning style approach can empower staff development to create an optimal environment for successful staff learning to assist in providing quality care with increasing retention (Yuh-Shiow Li et al 2011). And Paterson (2010) also reported that educators need to be aware of generational differences when working with nursing staff, they need to appreciate individual preferences in communication, when examining the learning factors in an aging workforce.

The results of the present study may support increasing faculty understanding of learning styles, as this understanding will be useful to both the students and the teachers who will encounter each other in learning settings. Developing knowledge of different learning styles among the student population is important in designing curricula, and adopting teaching methods that to promote student learning is a crucial part of ensuring that students engage positively with content and develop the deep learning skills needed for lifelong learning. 


\section{Macrothink Institute ${ }^{\mathrm{TM}}$

\section{Conclusion and Recommendations}

Based on the study findings of this study, it could be concluded that critical thinking is enhanced when active learning approaches. Overall of the present study revealed that there was no significant relationship between overall critical thinking dispositions and learning style with nursing students' achievement. This mean that critical thinking dispositions and learning style not improved as the academic years progressed. The majority of the undergraduate nursing students at Faculty of Nursing, King Khalid University regard of their academic year showed ambivalent disposition towards overall of the dispositional characteristics and the majority preferred visual/verbal learning style. They got the highest mean scores in the dispositional characteristics of truth seeking and open mindedness. Meanwhile, they got the lowest mean scores in the dispositional characteristics of self-confidence and maturity. A statistical significant difference was found in relation to overall critical thinking dispositions among nursing students.

Based on the findings study, the following recommendations were detected:

1. The findings of this research imply that nurse educators should use teaching methodologies and techniques to foster inquisitiveness instead of the passive teaching/ learning that takes place in a classroom.

2. Nurse educators must motivate their students to use critical thinking dispositions while solving problems and take decisions

3. Nurse educators must understand and integrate students' learning styles into nursing curricula to promote satisfying learning experiences

4. Additional research to identify teaching strategies that promote the development of critical thinking skills is needed.

5. It is essential for nursing education program to define the educational objectives that encourage faculty to cultivate students' critical thinking abilities and to develop curricula and teaching methods to fulfill such objectives and dealing with different learning styles.

6. Adopt creative approaches to transform students into interactive participants and open their minds and broaden and stimulate higher-level thinking and problem-solving abilities.

7. This study should be replicated in other faculties of nursing to in Saudi Arabia. 


\section{References}

1. Abu-Moghli, et al., (2005). Jordanian baccalaureate nursing students' perception of their learning styles. International Nursing Review, 52; 39-45.

2. Fleming, S., Mckee.G.. and Moore.S(2010). Undergraduate nursing students' learning styles: A longitudinal study, Nurse Educ. Today, doi:10.1016/j.nedt.2010.08.005.

3. Meehan-Andrews.T.A.(2009).Teaching mode efficiency and learning preferences of first year nursing students, Nurse Education Today,29; 24-32.

4. Yuan, H., Williams ,B and Fan,L.(2008).A systematic review of selected evidence on developing nursing students' critical thinking through problem-based learning, Nurse Education Today, 28; 657-663.

5. Kawashima,A. and Petrini,M.(2004). Study of critical thinking skills in nursing students and nurses in Japan, Nurse Education Today,24; 286-292.

6. Kelly Y.L. Ku. A. and Irene.T.(2010). Dispositional factors predicting Chinese students' critical thinking performance, Personality and Individual Differences, 48; 5458.

7. Facione, P.A., Facione, N.C., and Giancarlo, C.A.,( 2001). California Critical Thinking Disposition Inventory: Inventory Manual. California Academic Press, Millbrae, CA.

8. Ozturk, C, Muslu, G , and Dicle, A.(2008). A comparison of problem based and traditional education on nursing students' critical thinking dispositions, Nurse Education Today, 28; 627-632.

9. Simpson E, and Courtney. M.(2008). Implementation and evaluation of critical thinking strategies to enhance critical thinking skills in Middle Eastern nurses, International Journal of Nursing Practice; 14: 449-454.

10. Profetto-McGrath J.(2003). The relationship of critical thinking skills and critical thinking dispositions of baccalaureate nursing students. J Adv Nurs.;43(6):569-577.

11. Shirrell,D.(2008). Critical thinking as a predictor of success in an associate Teaching and Learning in Nursing,3, 131-136.

12. Yuh-Shiow, L. et al., (2011). An exploratory study of the relationship between age and learning styles among students in different nursing programs in Taiwan, Nurse Education Today, $31 ; 18-23$.

13. Sweet .S.L,(2009). Critical thinking and knowledge application utilizing a multifaceted group project incorporating diverse learning styles, Teaching and Learning in Nursing, 4, 34-36.

14. Astin, F., et al., (2006). The self-reported learning style preferences of female Macmillan clinical nurse specialist. Nurse Education Today, 26 (6); 475-483.

15. Li Y, Chen P, and Tsai S.(2008). A comparison of the learning styles among different nursing programs in Taiwan: implications for nursing education. Nurs. Educ. Today; 28: 70-76.

16. Felder, R., and Brent, R.,(2005). Understanding Student Differences. Journal of Engineering Education, 94 (1), 57-72. [Online] Available: http://www.highbeam.com/doc/1P3-792141541.html, accessed November 11, 2009.

17. Suliman,W.A.(2006).Critical thinking and learning styles of students in conventional and accelerated programmes International Nursing Review, 53 , 73-79. 
18. Felder, R.M., and Soloman,B.A. (2004). Index of Learning Styles. [Online] Available: http://www.ncsu.edu/felder-public/ILSpage.html, accessed November 12, 2009.

19. Taha, E. (2003). The dispositions of the undergraduate university nursing students toward critical thinking, Alexandria University, Master degree thesis, submitted to the Faculty of Nursing. .

20. Shin K, et al.,(2006). Critical thinking dispositions in baccalaureate nursing students. J. Adv. Nurs.; 56: 182-189.

21. Stewart, S., and Dempsey, L., (2005). A longitudinal study of baccalaureate nursing students' critical thinking dispositions. Journal of Nursing Education,44(2), 81-85.

22. Walsh, C.M. and Seldomridge,L.A.(2006). Measuring Critical Thinking One Step Forward, One Step Back, Nurse Educator, 31(4), 159-162.

23. Emir,S.(2009). Education faculty students' critical thinking disposition according to achedemic achievement, Procedia Social and Behavioral Sciences, 1;2466-2469.

24. Jackie H. et al.,(2007). Evaluation of critical thinking skills in an associate degree nursing program, Teaching and Learning in Nursing, 2, 109-115.

25. Ferol. J., et al., (2010) Critical thinking skills in nursing students: comparison of simulation-based performance with metrics. Journal of Advanced Nursing 66(10), 2182-2193. doi: 10.1111/j.1365-2648.2010.05385.x

26. Cook D.(2005). Reliability and validity of scores from the index of learning styles. Acad. Med.; 80: 97-101.

27. Felder R, and Spurlin J.(2005).Applications, reliability and validity of the Index of Learning Styles. Int. J. Eng. Educ.; 21: 103-112.

28. Suliman W, and Halabi J.(2006).Critical thinking and learning styles of students in conventional and accelerated programmes. Int. Nurs. Rev.; 53: 73-79.

29. Rassool, GH., and Rawaf, S. (2007). Learning style preferences of undergraduate nursing students. Nursing Standard. 21, 32,35-41

30. Zhang, $\mathrm{H}$ and Lambert, V.(2008). Critical thinking dispositions and learning styles of baccalaureate nursing students from China, Nursing and Health Sciences, 10, 175-181

31. Tao X, and Cui, Y. (2007).Study on the correlation between learning style and academic achievement of nursing students. J. Nurs. Sci.; 22:7-9 (in Chinese).

32. Astin, F., Closs, J.S., and Hughes, N., (2006). The self-reported learning style preferences of female Macmillan clinical nurse specialist. Nurse Education Today 26 (6), 475-483.

33. Arthurs, J. (2007). A juggling act in the classroom: Managing different learning styles. Teaching and Learning in Nursing, 2, 2-7.

34. Huxham, M. (2005). Learning in lectures: Do interactive windows help? Active Learning in Higher Education, 6(1), 17-31.

35. Koch, J., et al.,(2011). Learning preference as a predictor of academic performance in first year accelerated graduate entry nursing students: A prospective follow-up study, Nurse Educ. Today (2011), doi:10.1016/j.nedt.2010.10.019

36. D'Amore, A., et al., (2011).Learning styles of first-year undergraduate nursing and midwifery students: A cross-sectional survey utilising the Kolb Learning Style inventory, Nurse Educ. Today, doi:10.1016/j.nedt.2011.08.001 
37. Paterson, T., (2010). Generational considerations in providing critical care education. Critical Care Nursing Quarterly 33 (1), 67-74. 